\title{
Predictors and Outcome of Early-Onset Pneumonia After Out-of-Hospital Cardiac Arrest
}

\author{
Dirk Pabst MD, Sonja Römer MD, Alexander Samol MD, Philipp Kümpers MD, \\ Johannes Waltenberger MD, and Pia Lebiedz MD
}

\begin{abstract}
BACKGROUND: Early-onset pneumonia (EOP) after out-of-hospital cardiac arrest is frequently observed. Causative factors are loss of airway protection during cardiac arrest, pulmonary contusion, and emergency airway management. We assessed the incidence, risk factors, and clinical course of EOP, and evaluated the impact of an early exchange of the prehospitally inserted endotracheal tube (ETT). METHODS: In our retrospective analysis we included 104 consecutive subjects admitted to our ICU after out-of-hospital cardiac arrest between 2007 and 2012. All subjects underwent therapeutic hypothermia. We analyzed clinical course, inflammation indicators, Clinical Pulmonary Infection Score, occurrence of EOP, duration of ventilatory support, microbiological findings, and short-term outcome. RESULTS: Of the 104 subjects, $46.2 \%$ received an exchange of ETT directly after hospital admission. Neither ETT exchange nor observed aspiration were associated with elevated CPIS or EOP, nor with proof of microorganisms in respiratory secretions. We found no differences in duration of ventilatory support, $\mathrm{P}_{\mathrm{aO}_{2}} / \mathrm{F}_{\mathrm{IO}_{2}}, \mathrm{ICU}$ days, or outcome. C-reactive protein was significantly higher in subjects with aspiration $(P=.046)$. Sex, age, smoking status, aspiration, cause of cardiac arrest, first detected heart rhythm, and use of supraglottic airways devices were not associated with EOP. Subjects with EOP had a longer need for ventilatory support $(P=.005)$, higher tracheotomy rate $(P=.03)$, longer ICU stay $(P=.005)$, higher $C$-reactive protein $(P<.001)$, higher body temperature $(P=.003)$, higher Clinical Pulmonary Infection Score $(P<.001)$, and lower $\mathrm{P}_{\mathrm{aO}_{2}} / \mathrm{F}_{\mathrm{IO}_{2}}(P=.008)$. CONCLUSIONS: The rate of EOP was not significantly influenced by the exchange of the preclinically inserted ETT, but was associated with longer need for mechanical ventilation and ICU stay. Key words: pneumonia; cardiac arrest; aspiration; airway protection; emergency; airway management; endotracheal tube; Clinical Pulmonary Infection Score. [Respir Care 2013;58(9):1514-1520. (C) 2013 Daedalus Enterprises]
\end{abstract}

\section{Introduction}

During and after successful cardiopulmonary resuscitation (CPR) for out-of-hospital cardiac arrest (OHCA), the lungs are exposed to risks such as aspiration, pulmonary contusion by cardiocompression, emergency airway access, and ventilator-associated pneumonia (VAP). ${ }^{1}$ Earlyonset pneumonia (EOP) is the most frequent infectious complication shortly after OHCA. ${ }^{2}$

\footnotetext{
The authors are affiliated with the Department of Cardiovascular Medicine, with the exception of Dr Kümpers, who is affiliated with the Department of Internal Medicine D, University Hospital of Münster, Münster, Germany.
}

The authors have disclosed no conflicts of interest.
Diagnosis of EOP after OHCA can be difficult due to confounding factors, such as sepsis-like syndrome after $\mathrm{CPR}^{3}$ and influences of therapeutic hypothermia, ${ }^{4}$ so body temperature, heart rate, oxygenation indices, white blood cell count, and inflammation indicators ${ }^{5}$ are of questionable value for diagnosing pneumonia. Hence, various scoring systems have been tested to assess for EOP after $\mathrm{OHCA}^{4}$ or for VAP. ${ }^{6}$ Distinguishing between EOP and VAP is based mostly on the time of occurrence of pneu-

\footnotetext{
Correspondence: Dirk Pabst MD, Department of Cardiovascular Medicine, University Hospital of Muenster, Albert Schweitzer Campus 1, A1, 48149 Münster, Germany. E-mail: dirk.pabst@ukmuenster.de.
}

DOI: $10.4187 /$ respcare. 02307 
monia symptoms. Perbet et al defined EOP as pneumonia occurring within the first 3 days after OHCA, and VAP as pneumonia occurring during the further course of ventilatory support. ${ }^{4}$

One potentially influencing factor might be contamination of the endotracheal tube (ETT) during emergency airway access. By binding of bacteria in the trachea and being a bacteria reservoir inaccessible to host defense, the ETT promotes VAP. ${ }^{7}$ The inner surface of the ETT is rapidly colonized after insertion, and the ETT biofilm is a bacterial reservoir. ${ }^{8,9}$ Rello and colleagues identified male sex, trauma admission, and severity of underlying illness as independent risk factors for VAP. ${ }^{10}$ The study by Perbet et al revealed only therapeutic hypothermia to be an independent risk factor for EOP. ${ }^{4}$

We studied whether or not early exchange of the preclinically inserted ETT after OHCA influences the rate of EOP, EOP risk factors, and the consequences during ICU stay.

\section{Methods}

\section{Study Design}

After approval by our ethics board, we performed a retrospective observational study of all adult patients admitted to our medical ICU between 2007 and 2012, who had suffered OHCA and undergone CPR by the emergency medical service. The study was performed in accordance with the Helsinki declaration.

\section{Subjects}

All included subjects were comatose at hospital admission and underwent therapeutic hypothermia $\left(32-34^{\circ} \mathrm{C}\right)$ for 24 hours, by external cooling with ice packs and a cooling mat, as well as internal cooling by cold infusions. ETT changes were performed at random, assuming unsterile ETT handling during out-of-hospital CPR. The ETT was also exchanged if the preclinically inserted ETT was too small for the subject's body size. Supraglottic airway devices were replaced by ETT immediately after hospital admission. Patients were excluded if they died within the first 24 hours after hospital admission.

In addition to demographic factors, smoking status, observed aspiration during CPR, causes for cardiac arrest, first detected heart rhythm, and exchange of the ETT were obtained by medical chart review. Routine laboratory tests and physiological parameters, including Simplified Acute Physiology Score (SAPS) II, were obtained for each subject on admission and daily during up to day 10 . Whenever possible, we calculated the Clinical Pulmonary Infection Score (CPIS), ${ }^{11}$ including body temperature, white blood cell count, assessment of purulent tracheal secretions, $\mathrm{P}_{\mathrm{aO}_{2}}$ '

\section{QUICK LOOK}

\section{Current knowledge}

Early-onset pneumonia after out-of-hospital cardiac arrest is common and can be caused by loss of airway protection, pulmonary contusion, and emergency airway management.

\section{What this paper contributes to our knowledge}

The rate of early-onset pneumonia after out-of-hospital cardiac arrest was not significantly influenced by exchanging the endotracheal tube that had been inserted in pre-hospital care. Early-onset pneumonia was associated with longer mechanical ventilation and ICU stay.

$\mathrm{F}_{\mathrm{IO}_{2}}$, and chest x-ray between days 2-4 after ICU admission, using the Surgical Critical Care Net Web page (http:// www.surgicalcriticalcare.net/Resources/CPIS.php).

\section{Outcomes}

EOP (during the first 4 days after ICU admission) was the primary outcome. EOP was considered confirmed if respiratory secretions cultured positive for pathogenic microorganisms. Endobronchial fluid samples were gathered by bronchoalveolar lavage or endotracheal suctioning (the significance levels were $10^{3}$ up to $10^{5}$, dependent on dilution factor). In the absence of microbiological proof, pneumonia was assumed if the typical auscultation was combined with new pulmonary infiltration on x-ray (> $24 \mathrm{~h}$ ), inflammatory reaction, purulent endotracheal suctioning samples, and respiratory failure not explained by other causes such as pulmonary edema.

In-hospital mortality (for subjects who survived for $>24 \mathrm{~h}$ ) was defined as death in the hospital, versus the subject being discharged from the hospital alive.

We assessed the duration of overall ventilatory support, the need for tracheotomy, and the duration of endotracheal intubation (in subjects who survived for $>24 \mathrm{~h}$ ). We analyzed the ICU stay of all the subjects.

Secondary organ failure included renal and liver dysfunction, and was defined as acute kidney injury according to the Acute Kidney Injury Network ${ }^{12}$ and/or 5-fold elevation of liver transaminases above the upper reference values.

\section{Statistical Analysis}

Values are expressed as mean $\pm \mathrm{SD}$. Continuous variables were compared using the Mann-Whitney rank sum test or the Wilcoxon signed-rank test, as appropriate. Cat- 
Table 1. Comparison of Subjects With and Without Early-Onset Pneumonia

\begin{tabular}{|c|c|c|c|}
\hline & $\begin{array}{c}\text { Early-Onset Pneumonia } \\
n=54(51.9 \%)\end{array}$ & $\begin{array}{c}\text { No Early-Onset Pneumonia } \\
n=50(48.1 \%)\end{array}$ & $P$ \\
\hline Male, no. (\%) & $42(77.8)$ & $39(78)$ & $>.99$ \\
\hline Age, y & $56.3 \pm 16$ & $61 \pm 17$ & .16 \\
\hline Smoker, no. (\%) & $23(67.6)$ & $9(42.9)$ & .09 \\
\hline ICU mortality, no. (\%) & $11(20.4)$ & $13(26)$ & .64 \\
\hline Maximum SAPS II & $71 \pm 13$ & $72.2 \pm 21$ & .25 \\
\hline Aspiration, no. $(\%)$ & $22(40.7)$ & $12(24)$ & .09 \\
\hline Laryngeal tube, no. (\%) & $3(5.6)$ & $3(6)$ & $>.99$ \\
\hline Tube exchange, no. $(\%)$ & $26(48.1)$ & $22(44)$ & .70 \\
\hline Tracheotomy, no. (\%) & $29(53.7)$ & $16(32)$ & .03 \\
\hline Duration of mechanical ventilation, $h$ & $225 \pm 199$ & $128.3 \pm 145.5$ & .005 \\
\hline Duration of orotracheal intubation, $\mathrm{h}$ & $95.3 \pm 77$ & $68.6 \pm 51.8$ & .03 \\
\hline Antibiotic treatment, no. $(\%)$ & $45(90)$ & $33(76.7)$ & .07 \\
\hline ICU days & $12.8 \pm 9.5$ & $8.7 \pm 7.4$ & .005 \\
\hline Organ failure, no. (\%) & $14(25.9)$ & $15(30)$ & .67 \\
\hline Required reintubation, no. (\%) & $1(2)$ & $2(4)$ & .62 \\
\hline Maximum C-reactive protein, $\mathrm{mg} / \mathrm{dL}$ & $18.9 \pm 8.2$ & $12.2 \pm 7.6$ & $<.001$ \\
\hline Maximum leukocytes, thousand/ $\mu \mathrm{L}$ & $17.4 \pm 6.3$ & $16.4 \pm 6.1$ & .32 \\
\hline Maximum body temperature, ${ }^{\circ} \mathrm{C}$ & $38.5 \pm 0.9$ & $38.2 \pm 0.9$ & .003 \\
\hline Maximum Clinical Pulmonary Infection Score & $5.1 \pm 1.9$ & $3 \pm 1.5$ & $<.001$ \\
\hline \multicolumn{4}{|l|}{$\mathrm{P}_{\mathrm{aO}_{2}} / \mathrm{F}_{\mathrm{IO}_{2}}, \mathrm{~mm} \mathrm{Hg}$} \\
\hline At admission & $259 \pm 128$ & $285 \pm 106$ & .24 \\
\hline Minimum & $141 \pm 49$ & $182 \pm 76$ & .008 \\
\hline $\begin{array}{l} \pm \text { Values are mean } \pm \text { SD. } \\
\text { SAPS }=\text { Simplified Acute Physiology Score }\end{array}$ & & & \\
\hline
\end{tabular}

egorical variables were compared using the chi-square test. Correlations between variables were assessed with the Spearman rank correlation coefficient or Pearson correlation, as appropriate. Simple and multiple linear regression and binary logistic regression models were used to identify predictors of EOP or CPIS, as well as days of ventilatory support, ICU days, hospital mortality, and occurrence of severe sepsis, respectively. All tests were 2-sided, and significance was accepted at $P<.05$. Data analysis was performed with statistics software (SPSS 20, SPSS, Chicago, Illinois).

\section{Results}

We included 104 subjects who survived CPR after OHCA. All subjects were treated with therapeutic hypothermia. Most subjects (94.2\%) had been orotracheally intubated by the emergency medical service during cardiocompression. In 6 subjects $(5.8 \%)$ a supraglottic airway device (King LT Supralaryngeal Airway, King Systems, Noblesville, Indiana) was applied.

The mean age was $58.5 \pm 16.7$ years, and $77.9 \%$ were male. Most of the cardiac arrests were caused by primary cardiac disorders $(n=85,81.7 \%)$. In 18 subjects $(17.3 \%)$ cardiac arrest was caused by respiratory failure or asphyxia.
In one subject the cause of cardiac arrest remained obscure. The first detected heart rhythm was ventricular fibrillation or pulseless ventricular tachycardia in 75\%, asystole in $23.1 \%$, and electromechanical dissociation in $1.9 \%$.

The overall hospital mortality was $23.1 \%(n=24)$. A total of $13(12.5 \%)$ subjects were directly discharged from the hospital, and $67(64.4 \%)$ were transferred to other hospitals or to rehabilitation centers. A total of 48 (46.2\%) subjects received an exchange of ETT immediately after hospital admission, and in $56(53.8 \%)$ subjects the preclinically inserted ETT was left in.

\section{Microorganisms Found in Respiratory Secretions, and Antibiotic Treatment}

In 25 (24\%) subjects we found pathogenic microorganisms in respiratory secretions. In 15 subjects, Staphylococcus aureus was found (of these 2 were methicillinresistant $S$. aureus), 3 subjects had Streptococcus species, 3 had Escherichia coli, 1 had Enterobacter aerogenes, 1 had Aspergillus fumigatus, 1 had Klebsiella pneumoniae, 2 had Haemophilus influenzae, and 3 had Candida glabrata. In 7 subjects, Candida albicans was found in respiratory secretions, which mostly represents a colonization rather than an infection. Only one subject had a positive blood 
Table 2. Comparison of Subjects With and Without Exchange of Endotracheal Tube

\begin{tabular}{|c|c|c|c|c|}
\hline & $\begin{array}{c}\text { All } \\
\text { Subjects } \\
n=104\end{array}$ & $\begin{array}{c}\text { Tube } \\
\text { Exchange } \\
n=48\end{array}$ & $\begin{array}{c}\text { No Tube } \\
\text { Exchange } \\
n=56\end{array}$ & $P$ \\
\hline Male, no. (\%) & $81(77.9)$ & $40(83.3)$ & $41(73.2)$ & .24 \\
\hline Age, mean $\pm \mathrm{SD}$ y & $58.5 \pm 16.7$ & $56.3 \pm 17.7$ & $60.4 \pm 15.8$ & .21 \\
\hline ICU mortality, no. (\%) & $24 \pm 23.1$ & $10 \pm 20.8$ & $14 \pm 25.5$ & .21 \\
\hline Maximum SAPS II & $71.6 \pm 17.2$ & $69.5 \pm 22.7$ & $72.7 \pm 13.5$ & .74 \\
\hline Aspiration, no. (\%) & $34(32.7)$ & $19(39.6)$ & $15(26.7)$ & .21 \\
\hline Tracheotomy, no. (\%) & $45(43.3)$ & $20(41.7)$ & $25(44.5)$ & .84 \\
\hline Duration of mechanical ventilation, $\mathrm{h}$ & $180.2 \pm 182.5$ & $164 \pm 168$ & $195 \pm 195$ & .56 \\
\hline Ventilator-free days & $15.5 \pm 10.8$ & $16.5 \pm 10.6$ & $14.6 \pm 11.1$ & .48 \\
\hline Pathogenic microorganisms, no. (\%) & $25(24)$ & $13(27.1)$ & $12(21.4)$ & .65 \\
\hline Antibiotic treatment, no. $(\%)$ & $78(75)$ & $42(87.5)$ & $36(64.3)$ & .09 \\
\hline ICU days & $10.8 \pm 8.7$ & $9.4 \pm 7.6$ & $12 \pm 9.6$ & .13 \\
\hline ICU-free days & $13.3 \pm 10$ & $14.9 \pm 9.7$ & $12 \pm 10.1$ & .14 \\
\hline Organ failure, no. $(\%)$ & $28(26.9)$ & $11(22.9)$ & $18(32.1)$ & .38 \\
\hline Required reintubation, no. (\%) & $3(2.9)$ & $2(3.8)$ & $1(2.1)$ & $>.99$ \\
\hline Maximum C-reactive protein, $\mathrm{mg} / \mathrm{dL}$ & $15.6 \pm 8.5$ & $15.5 \pm 8.4$ & $15.8 \pm 8.8$ & .98 \\
\hline Maximum leukocytes, thousand/ $\mu \mathrm{L}$ & $16.9 \pm 6.3$ & $16 \pm 5.7$ & $17.8 \pm 6.6$ & .16 \\
\hline Maximum body temperature, ${ }^{\circ} \mathrm{C}$ & $38.4 \pm 0.9$ & $38.3 \pm 0.8$ & $38.4 \pm 0.9$ & .97 \\
\hline Early-onset pneumonia, no. (\%) & $53(51)$ & $26(54.2)$ & $27(48.2)$ & .56 \\
\hline Maximum Clinical Pulmonary Infection Score & $4 \pm 2$ & $4.4 \pm 2.3$ & $3.8 \pm 1.8$ & .33 \\
\hline \multicolumn{5}{|l|}{$\mathrm{P}_{\mathrm{aO}_{2}} / \mathrm{F}_{\mathrm{IO}_{2}}, \mathrm{~mm} \mathrm{Hg}$} \\
\hline At admission & $271.4 \pm 118.2$ & $279.5 \pm 120.6$ & $264.4 \pm 117$ & .64 \\
\hline Minimum & $160.5 \pm 66$ & $159.6 \pm 73.5$ & $161.3 \pm 60$ & .66 \\
\hline
\end{tabular}

culture with proof of $H$. influenzae, in one case we found Streptococcus mitis, and 4 subjects had coagulase-negative staphylococci, which were contamination rather than infection.

A total of 78 subjects $(75 \%)$ received early antibiotic treatment, with a trend toward more frequent use in subjects with EOP: $90 \%$ antibiotic treatment in subjects with EOP vs $76.7 \%$ in subjects without $(P=.07)$.

\section{Risk Factors for Occurrence of Early-Onset Pneumonia}

Linear regression analysis found that $\operatorname{sex}(\beta=-0.091$, $95 \% \mathrm{CI}-2.613$ to $1.364, P=.53)$, age $(\beta=0.078$, 95\% CI $0.035-0.06, P=.59)$, cause of cardiac arrest ( $\beta=0.357,95 \% \mathrm{CI}-1.342$ to $4.554, P=.28)$, first detected heart rhythm $(\beta=0.252,95 \% \mathrm{CI}-1.359$ to $3.258, P=.41)$, smoker status $(\beta=0.258,95 \% \mathrm{CI}-0.314$ to $2.287, P=.13)$, confirmed aspiration $(\beta=0.1$, $95 \%$ CI -1.097 to $1.731, P=.64)$, use of supraglottic airway device $(\beta=0.135,95 \% \mathrm{CI}-1.597$ to 3.715 , $P=.42)$, and change of ETT $(\beta=0.118,95 \% \mathrm{CI}-1.024$ to $1.683, P=.63)$ did not influence CPIS or the occurrence of EOP: sex: odds ratio 1.93, 95\% CI 0.26-14.53, $P=.53$; age: odds ratio $0.99,95 \%$ CI $0.96-1.04, P=.95$; cause of cardiac arrest: odds ratio $0.72,95 \%$ CI $0.03-$ $16.48, P=.84$; first detected heart rhythm: odds ratio $0.38,95 \%$ CI $0.03-4.68, P=.45$; smoking status: odds ratio $2.86,95 \%$ CI $0.84-9.76, P=.09$; aspiration: odds ratio $1.37,95 \% \mathrm{CI} 0.38-4.88, P=.63$; use of supraglottic airway device: odds ratio $0.71,95 \%$ CI $0.05-10.82, P=.80$; exchange of ETT: odds ratio $1.22,95 \%$ CI $0.34-4.33$, $P=.76$.

\section{Clinical Consequences of Early-Onset Pneumonia}

Subjects with EOP had longer mechanical ventilation $(225 \pm 199 \mathrm{~h}$ vs $128.3 \pm 145.5 \mathrm{~h}, P=.005)$, a higher rate of tracheotomy $(53.7 \%$ vs $32 \%, P=.03)$, longer duration of orotracheal intubation $(95.3 \pm 77 \mathrm{~h}$ vs $68.6 \pm 51.8 \mathrm{~h}$, $P=.03)$, and longer ICU stay $(12.8 \pm 9.5 \mathrm{~d}$ vs $8.7 \pm 7.4 \mathrm{~d}$, $P=.005)$.

During the first 4 days after admission, the EOP subjects had a higher maximum body temperature $(P=.003)$, a higher maximum $C$-reactive protein $(P<.001)$, a higher maximum CPIS $(P<.001)$, and a lower minimum $\mathrm{P}_{\mathrm{aO}_{2}} / \mathrm{F}_{\mathrm{IO}_{2}}(P=.008)$ than the subjects without EOP, whereas the maximum leukocyte count did not differ significantly (Table 1). 
Table 3. Comparison of Subjects With and Without Confirmed Aspiration

\begin{tabular}{|c|c|c|c|c|}
\hline & $\begin{array}{c}\text { All Subjects } \\
n=104\end{array}$ & $\begin{array}{c}\text { Confirmed } \\
\text { Aspiration } \\
n=34\end{array}$ & $\begin{array}{c}\text { No } \\
\text { Aspiration } \\
n=70\end{array}$ & $P$ \\
\hline Male, no. (\%) & $81(77.9)$ & $29(85.3)$ & $52(74.3)$ & .22 \\
\hline Age, mean \pm SD y & $58.5 \pm 16.7$ & $56 \pm 17.1$ & $59.7 \pm 16.5$ & .29 \\
\hline ICU mortality, no. (\%) & $24(23.1)$ & $6(17.6)$ & $18(25.7)$ & .46 \\
\hline Maximum SAPS II & $71.6 \pm 17.2$ & $72.2 \pm 16.6$ & $71.2 \pm 15.3$ & .54 \\
\hline Tracheotomy, no. (\%) & $45(43.3)$ & $17(50)$ & $28(40)$ & .40 \\
\hline Duration of mechanical ventilation, $\mathrm{h}$ & $180.2 \pm 182.5$ & $202 \pm 215$ & $168 \pm 164$ & .48 \\
\hline Ventilator-free days & $15.5 \pm 10.8$ & $16 \pm 10.6$ & $15.2 \pm 11$ & .89 \\
\hline Pathogenic microorganisms, no. (\%) & $25(24)$ & $9(26.5)$ & $16(22.9)$ & .81 \\
\hline Antibiotic treatment, no. (\%) & $78(75)$ & $30(90.9)$ & $48(80)$ & .24 \\
\hline ICU days & $10.8 \pm 8.7$ & $10.7 \pm 8.9$ & $10.8 \pm 8.8$ & .93 \\
\hline ICU-free days & $13.3 \pm 10$ & $14.3 \pm 9.9$ & $12.8 \pm 10.2$ & .62 \\
\hline Organ failure, no. $(\%)$ & $28(26.9)$ & $9(26.5)$ & $20(28.6)$ & $>.99$ \\
\hline Required reintubation, no. (\%) & $3(2.9)$ & 0 & $4(4.4)$ & .33 \\
\hline Maximum C-reactive protein, $\mathrm{mg} / \mathrm{dL}$ & $15.6 \pm 8.5$ & $18.1 \pm 8.9$ & $14.5 \pm 8.2$ & .046 \\
\hline Maximum leukocytes, thousand/ $\mu \mathrm{L}$ & $16.9 \pm 6.3$ & $16.5 \pm 5.5$ & $17.1 \pm 6.6$ & .95 \\
\hline Maximum body temperature, ${ }^{\circ} \mathrm{C}$ & $38.4 \pm 0.9$ & $38.4 \pm 0.9$ & $38.3 \pm 0.9$ & .45 \\
\hline Early-onset pneumonia, no. (\%) & $53(51)$ & $22(64.7)$ & $31(44.3)$ & .09 \\
\hline Maximum Clinical Pulmonary Infection Score & $4 \pm 2$ & $4.4 \pm 2$ & $3.8 \pm 2$ & .17 \\
\hline \multicolumn{5}{|l|}{$\mathrm{P}_{\mathrm{aO}_{2}} / \mathrm{F}_{\mathrm{IO}_{2}}, \mathrm{~mm} \mathrm{Hg}$} \\
\hline At admission & $271.4 \pm 118.2$ & $305 \pm 136$ & $258 \pm 109$ & .13 \\
\hline Minimum & $160.5 \pm 66$ & $156 \pm 75$ & $163 \pm 62$ & .54 \\
\hline $\begin{array}{l} \pm \text { Values are mean } \pm \text { SD. } \\
\text { SAPS }=\text { Simplified Acute Physiology Score }\end{array}$ & & & & \\
\hline
\end{tabular}

Although the duration of ventilatory support and ICU stay were longer in subjects with EOP, the overall outcome did not differ between the groups with and without EOP (data not shown).

\section{Impact of Endotracheal Tube Change}

We found no significant differences in CPIS, EOP occurrence, or inflammation indicators (body temperature, C-reactive protein, and leukocyte count) between those with or without ETT change. The groups did not differ significantly with regard to frequency of proven infection, need for antibiotics, tracheotomy rate, or $\mathrm{P}_{\mathrm{aO}_{2}} / \mathrm{F}_{\mathrm{IO}_{2}}$. Furthermore, there were no differences in duration of ventilatory support, maximum SAPS II, occurrence of additional organ failure, ICU days, or survival (Table 2). The reintubation rate was low $(2.9 \%)$, and showed no association with ETT exchange.

\section{Impact of Aspiration}

In $34(32.7 \%)$ subjects the emergency medical team confirmed aspiration during CPR, by visual diagnosis. Subjects with proven aspiration did not have significantly different CPIS, $\mathrm{P}_{\mathrm{aO}_{2}} / \mathrm{F}_{\mathrm{IO}_{2}}$, SAPS II, mortality rates, or ICU stay. We found significantly higher maximum C-reactive protein in subjects with confirmed aspiration (18.1 \pm $8.9 \mathrm{mg} / \mathrm{dL})$, compared to those without $(14.5 \pm 8.2 \mathrm{mg} /$ $\mathrm{dL}, P=.046)$, whereas maximum leukocyte count and maximum body temperature did not differ significantly (Table 3). Furthermore, we observed a trend toward a higher EOP rate in subjects with proven aspiration $(64 \%$ EOP in subjects with aspiration vs $44.3 \%$ in subjects without, $P=.09$ ).

\section{Inflammation Indicators in Pneumonia After OHCA}

The Figure displays the course of $\mathrm{P}_{\mathrm{aO}_{2}} / \mathrm{F}_{\mathrm{IO}_{2}}$, leukocytes, and $\mathrm{C}$-reactive protein during the first 10 days after $\mathrm{OHCA}$. We found significant differences in C-reactive protein und $\mathrm{P}_{\mathrm{aO}_{2}} / \mathrm{F}_{\mathrm{IO}_{2}}$ between the EOP and no-EOP subjects during days 4-7 after hospital admission.

\section{Discussion}

The causes of EOP after successful pre-hospital CPR are multiple. The consequences of EOP, such as prolonged ventilatory support and ICU stay, are of clinical and financial importance. The measures taken to prevent EOP after OHCA are very limited. We tested for the first time 

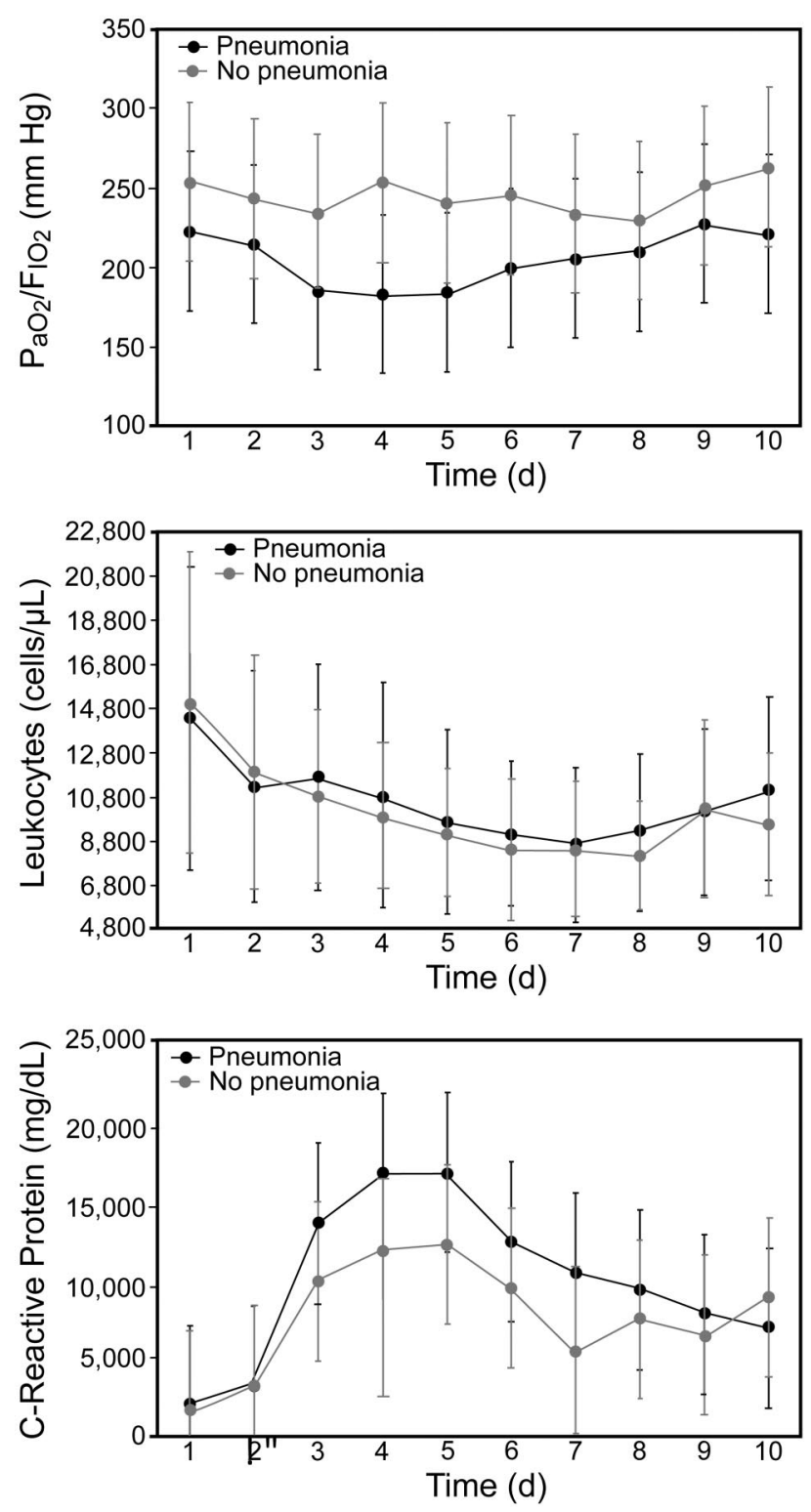

Figure. $\mathrm{P}_{\mathrm{aO}_{2}} / \mathrm{F}_{1 \mathrm{O}_{2}}$, leukocyte count, and C-reactive protein during the first 10 days after out-of-hospital cardiac arrest, in subjects with or without early-onset pneumonia. For $\mathrm{P}_{\mathrm{aO}_{2}} / \mathrm{F}_{\mathrm{IO}_{2}}$ there were significant differences on day $4(P=.009)$, day $5(P=.003)$, and day $6(P=.03)$. For leukocyte count there were no significant differences. For $C$-reactive protein there were significant differences on day $3(P=.006)$, day $4(P=.052)$, and day $7(P=.02)$.

the hypothesis that the incidence of EOP can be influenced by early exchange of the preclinically inserted and potentially contaminated ETT.

\section{Impact of Early ETT Change Under Sterile Conditions}

Although the EOP is caused by different factors, such as aspiration, pulmonary contusion by cardiocompression, and emergency airway access, rather than only by ventilator-associated lung injury, EOP and VAP might have some etiologic factors in common. For VAP, different measures have been tested to reduce the VAP rate in intensive care patients. ${ }^{13-15}$ Most of them aim at a reduction of bacterial colonization of the ETT. Assuming an additional contamination of the ETT during pre-hospital emergency airway access, we herein report for the first time results of ETT exchange under sterile conditions after hospital admission. We did not detect differences in clinical course, inflammation indicators, or EOP rate after ETT exchange, compared to subjects without ETT exchange. Hence, ETT exchange does not present an effective means for reduction of pneumonia rates. Neither demographic factors, such as age, sex, and smoking habits, nor clinical features, such as cause of cardiac arrest or confirmed aspiration, were significant risk factors for EOP.

\section{Use of CPIS for Diagnosis of EOP After OHCA}

Due to known difficulties in diagnosing EOP after CPR for OHCA, we evaluated the CPIS ${ }^{11}$ and showed a good correlation with previously used pneumonia scores after $\mathrm{OHCA}^{4} \mathrm{C}$-reactive protein and body temperature were predictors of EOP, whereas leukocyte count, which is a factor in the CPIS, ${ }^{11}$ did not show a good correlation with EOP in our subjects.

\section{Impact of Supraglottic Airway Devices}

Supraglottic airway devices are of growing importance in preclinical emergency management. A recent study demonstrated favorable outcomes in subjects treated with primary ETT, instead of supraglottic airway devices, during pre-hospital CPR. ${ }^{16}$ Although in our cohort only 6 subjects were admitted to hospital with laryngopharyngeal tube, we did not find an elevated rate of EOP in these subjects, which clearly supports the use of these devices.

\section{Impact of Microbiologic Findings and Antibiotic Treatment}

A recent study by Davies et al ${ }^{17}$ showed better outcomes in OHCA patients who received early antibiotic treatment within the first 7 days. In our cohort, $75 \%$ of all subjects received antibiotic treatment, with a trend toward more antibiotic use in subjects with EOP than in those without. We take this fact as a consequence of the proven or suspected infection. Our data may not further contribute to the question of whether early antibiotic treatment influences the outcome.

There are certain limitations of this study to be addressed. First, the study design was retrospective. Second, pneumonia scores such as CPIS and EOP score are partly 
subjective, due to the differential evaluation of pneumonic infiltrations on x-ray and the difficulties in x-ray interpretation in supine ventilated subjects. Furthermore, ICU days and duration of mechanical ventilation are caused not only by respiratory failure, but often are a consequence of bad neurological outcome. The subject's outcome is caused by underlying disease and complications rather than by the occurrence of EOP. Therefore, the impact of EOP on ICU course is very limited.

\section{Conclusions}

In summary, our study failed to identify influenceable factors for EOP after successful CPR of OHCA patients. As previously reported, the occurrence of EOP is associated with longer need for ventilatory support and longer ICU duration, and might therefore lead to high healthcare costs.

\section{REFERENCES}

1. Bjork RJ, Snyder BD, Campion BC, Loewenson RB. Medical complications of cardiopulmonary arrest. Arch Intern Med 1982;142(3): 500-503.

2. Mongardon N, Perbet S, Lemiale V, Dumas F, Poupet H, Charpentier J, et al. Infectious complications in out-of-hospital cardiac arrest patients in the therapeutic hypothermia era. Crit Care Med 2011; 39(6):1359-1364.

3. Adrie C, Laurent I, Monchi M, Cariou A, Dhainaou JF, Spaulding C. Postresuscitation disease after cardiac arrest: a sepsis-like syndrome? Curr Opin Crit Care 2004;10(3):208-212.

4. Perbet S, Mongardon N, Dumas F, Bruel C, Lemiale V, Mourvillier B, et al. Early-onset pneumonia after cardiac arrest: characteristics, risk factors and influence on prognosis. Am J Respir Crit Care Med 2011;184(9):1048-1054.

5. Mongardon N, Lemiale V, Perbet S, Dumas F, Legriel S, Guérin S, et al. Value of procalcitonin for diagnosis of early onset pneumonia in hypothermia-treated cardiac arrest patients. Intensive Care Med 2010, 36(1):92-99.
6. Schurink CA, Van Nieuwenhoven CA, Jacobs JA, Rozenberg-Arska $\mathrm{M}$, Joore HC, Buskens E, et al. Clinical pulmonary infection score for ventilator-associated pneumonia: accuracy and inter-observer variability. Intensive Care Med 2004;30(2):217-224.

7. Levine SA, Niederman MS. The impact of tracheal intubation on host defenses and risks for nosocomial pneumonia. Clin Chest Med 1991;12(3):523-543.

8. Adair CG, Gorman SP, Feron BM, Byers LM, Jones DS, Goldsmith $\mathrm{CE}$, et al. Implications of endotracheal tube biofilm for ventilatorassociated pneumonia. Intensive Care Med 1999;25(10):1072-1076.

9. Inglis TJ, Millar MR, Jones JG, Robinson DA. Tracheal tube biofilm as a source of bacterial colonization of the lung. J Clin Microbiol 1989;27(9):2014-2018.

10. Rello J, Ollendorf DA, Oster G, Vera-Llonch M, Bellm L, Redman R, Kollef MH; VAP Outcomes Scientific Advisory Group. Epidemiology and outcomes of ventilator-associated pneumonia in a large US database. Chest 2002;122(6):2115-2121.

11. Pugin J, Auckenthaler R, Mili N, Janssens JP, Lew PD, Suter PM. Diagnosis of ventilator-associated pneumonia by bacteriologic analysis of bronchoscopic and nonbronchoscopic "blind" bronchoalveolar lavage fluid. Am Rev Respir Dis 1991;143(5 Pt 1):1121-1129.

12. Mehta RL, Kellum JA, Shah SV, Molitoris BA, Ronco C, Warnock DG, Levin A; Acute Kidney Injury Network. Report of an initiative to improve outcomes in acute kidney injury. Crit Care 2007;11(2): R31.

13. Rello J, Afessa B, Anzueto A, Arroliga AC, Olson ME, Restrepo MI, et al. Activity of a silver-coated endotracheal tube in preclinical models of ventilator-associated pneumonia and a study after extubation. Crit Care Med 2010;38(4):1135-1140.

14. Kollef MH, Afessa B, Anzueto A, Veremakis C, Kerr KM, Margolis $\mathrm{BD}$, et al; NASCENT Investigation Group. Silver-coated endotracheal tubes and incidence of ventilator-associated pneumonia: the NASCENT randomized trial. JAMA 2008;300(7):805-813.

15. Coppadoro A, Berra L, Bigatello LM. Modifying endotracheal tubes to prevent ventilator-associated pneumonia. Curr Opin Infect Dis 2011;24(2):157-162.

16. Wang HE, Szydlo D, Stouffer JA, Lin S, Carlson JN, Vaillancourt C, et al; ROC Investigators. Endotracheal intubation versus supraglottic airway insertion in out-of-hospital cardiac arrest. Resuscitation 2012; 83(9):1061-1066.

17. Davies KJ, Walters JH, Kerslake IM, Greenwood R, Thomas MJ. Early antibiotics improve survival following out-of hospital cardiac arrest. Resuscitation 2013;84(5):616-619. 